\title{
Low- vs high-frequency repetitive transcranial magnetic stimulation as an add-on treatment for refractory depression
}

\author{
Julien Eche ${ }^{1,2,3}$, Marine Mondino ${ }^{1,2,3}$, Frederic Haesebaert ${ }^{1,2,3}$, Mohamed Saoud ${ }^{1,2,3}$, Emmanuel Poulet ${ }^{1,2,3}$ \\ and Jerome Brunelin ${ }^{1,2,3}$ * \\ ${ }^{1}$ Université de Lyon, Lyon, France \\ 2 Université Lyon 1, Lyon, France \\ ${ }^{3}$ EA4615, Centre Hospitalier Le Vinatier, Bron, France
}

\section{Edited by:}

William McDonald, Emory University

School of Medicine, USA

\section{Reviewed by:}

Christopher A. Wall, Mayo Clinic, USA Wonnei Caumo, Universidade Federal do Rio Grande do Sul, Brazil

\section{*Correspondence:}

Jerome Brunelin, EA 4615, Pôle EST,

Centre Hospitalier Le Vinatier, 95

Boulevard Pinel, 69677 Bron Cedex

France.

e-mail: jerome.brunelin@

ch-le-vinatier.fr
Objectives: Repetitive transcranial magnetic stimulation (rTMS) seems to be effective as an antidepressant, however, some confusion remains about the best parameters to apply and the efficacy of its association with pharmacological antidepressant treatments. Method: In a single blind randomized study 14 patients with unipolar resistant depression to one antidepressant treatment were enrolled to receive, in combination with venlafaxine $(150 \mathrm{mg}$ ), either 20 sessions of $10 \mathrm{~Hz}$ rTMS (2000 pulses per session) applied over the left dorsolateral prefrontal cortex (DLPFC) or 20 sessions of $1 \mathrm{~Hz}$ rTMS (120 stimulations per sessions) applied over the right DLPFC. Results: A similar antidepressant effect was observed in both groups with a comparable antidepressant delay of action (2 weeks) and a comparable number of responders (MADRS $<15$ ) after 4 weeks of daily rTMS sessions (66 vs 50\%). Conclusion: Low- and high-frequency rTMS seems to be effective as an add-on treatment to venlafaxine as monotherapy in pharmacological refractory major depression (stage 1). Due to its short duration (one session of $1 \mathrm{~Hz}$ rTMS lasts 4 min vs 16 for $10 \mathrm{~Hz}$ rTMS) and its safety, low frequency rTMS may be a useful alternative treatment for patients with refractory depression.

Keywords: transcranial magnetic stimulation, dorsolateral prefrontal cortex, rTMS, venlafaxine, depression

\section{INTRODUCTION}

Depression constitutes a major public health concern with a considerably high level of morbidity and mortality. Although antidepressant $(\mathrm{AD})$ treatments have demonstrated their efficiency, a substantial number of depressed patients (50-60\%) respond only partially or not at all to at least one trial of an antidepressant medication (Steffens et al., 1997) and close to $20 \%$ of these patients are refractory to any antidepressant medication (Fava, 2003). Moreover, the clinical utility of antidepressant drugs is impaired by the delay in onset of their therapeutic action.

Most of recent studies as well as meta-analysis support an antidepressant effect of high frequency (HF) repetitive transcranial magnetic stimulation (rTMS) applied to the left dorsolateral prefrontal cortex (LDLPFC; George et al., 2010; for review: Brunelin et al., 2007). However there remains some confusion about the best beneficial stimulation site to target as well as the best parameters to apply. While the impact of starting a combination between rTMS and an $\mathrm{AD}$ at the same time is still poorly studied, some authors support the hypothesis that this association could shorten the AD treatment delay of action (Poulet et al., 2004; Rumi et al., 2005). On the other hand, there is growing evidence that HF LDLPFC is as effective as low frequency (LF) rTMS applied to the right DLPFC (RDLPFC) in the treatment of depressive episode (Höppner et al., 2003; Isenberg et al., 2005; Stern et al., 2007; Fitzgerald et al., 2009; Pallanti et al., 2010; Rossini et al., 2010).
We report here results from a pilot single blind double arms controlled study investigating the antidepressant effect, in association with venlafaxine, of active HF $(10 \mathrm{~Hz})$ LDLPFC rTMS compared to active LF $(1 \mathrm{~Hz})$ LDLPFC rTMS $(150 \mathrm{mg})$ in patient with refractory depressive symptoms.

\section{MATERIALS AND METHODS}

Sixteen patients with unipolar major depression according to DSM IV were included through clinical and MINI evaluation (Mini version 4.4). All of them gave their written informed consent before entering the study which was approved by a regional ethical committee. They were aged between 18 and 65 and have not tried venlafaxine for the present depression episode. Patients were recruited at the "Le vinatier" Hospital. At inclusion, all of them present a Montgomery and Asberg (1979) Depression Rating Scale (MADRS) score $>20$ despite the prescription of an $\mathrm{AD}$ at efficient dose for at least 12 weeks. Patients respond to stage 1 of treatment-resistant depression as described in Fava (2003).

Prospective patients were screened for contraindications to rTMS, including a history of personal or family seizures, neurological or neurosurgical antecedent, inner ear prosthesis, pacemaker, and anticonvulsive medication. Electroencephalographic and clinical examination was made before the first rTMS sequence.

Participants were randomly allocated into two groups after 2 weeks of wash out period for all medications. Venlafaxine 
(75 mg/day) administration as monotherapy began 3 days before the start of rTMS treatment. The day of the first rTMS session, venlafaxine was increased to $150 \mathrm{mg}$ on the morning. Then, one group was treated with venlafaxine and HF-rTMS applied over the LDLPFC and the second group was treated with venlafaxine and LF-rTMS applied over the RDLPFC.

Stimulations were carried out using a MagPro 100 (MedtronicBoulogne-France) stimulator system using figure-eight $70-\mathrm{mm}$ coils. Stimulation intensity was $100 \%$ of resting motor threshold. Motor threshold was identified as the minimum magnetic field strength required to produce left thenar muscle activation by single transcranial magnetic pulses delivered to the motor cortex for at least 5 of 10 trials. Coil placement was $5 \mathrm{~cm}$ anterior from motor cortex (international 10-20 system). Because two patients withdrew their consent before the start of the trial, the final groups were:

- High-frequency group $(n=6)$ : Stimulation frequency was $10 \mathrm{~Hz}$. Each patient received 10, 15, or 20 rTMS sessions depending on the response rate after 10 sessions, one session per day ( 2 or 4 weeks). Each daily session consisted in a total of 2000 pulses 40 trains of $5 \mathrm{~s}$ duration and $30 \mathrm{~s}$ intertrain intervals.

- Low frequency group $(n=8)$ : Stimulation frequency was $1 \mathrm{~Hz}$. Each patient received 10, 15, or 20 rTMS sessions depending on the response rate after 10 sessions, one session per day ( 2 or 4 weeks). Each daily session consisted in a total of 120 pulses of 2 trains of $60 \mathrm{~s}$ duration and $120 \mathrm{~s}$ intertrain intervals.

A psychiatrist blind to group assignment conducted all assessments of patients' symptoms. To assess antidepressant effects, we used the 10-items MADRS. We measured MADRS scores at baseline, after 5, 10, 15, and 20 rTMS sessions. Patients who were responders after the first 10 or 15 rTMS sessions (defined as MADRS score $<15$ ) did not received more rTMS sessions.

\section{ANALYSIS}

Comparisons between groups at baseline were assessed using student $t$-tests except for gender (Fischer's chi-square). Statistical analysis was performed at a significant threshold of 0.05 using a repeated measures analysis of variance (ANOVA) on MADRS scores at each assessment times. Number of responders was compared between the groups using Fischer's chi-square test. Statistics were done using the Statistica software.

\section{RESULTS}

At baseline, the two groups did not significantly differ for age, sex ratio, and for MADRS scores (Table 1). No adverse event was observed in both groups.

Number of responders did not differ in each group at each assessment $\left(\chi^{2}=0.4 ; \mathrm{dl}=1 ; p=0.57\right)$. First responders (MADRS $<15)$ were observed after 10 rTMS session in both groups (Table 1). More than $50 \%$ of patients were responders at the end of the study period (4 weeks).

Effect of treatment (time) was significant in both group $\left[F_{(4,44)}=15.42 ; p<10^{-7}\right]$. No significant statistical difference was observed for MADRS scores between the two groups $\left[F_{(1,11)}=0.32 ; p=0.58\right]$. We reported no interaction between
Table 1 | Characteristics of patients throughout the study period.

\begin{tabular}{|c|c|c|c|}
\hline & $1 \mathrm{~Hz}(n=8)$ & $10 \mathrm{~Hz}(n=6)$ & $p$ \\
\hline \multicolumn{4}{|c|}{ BASELINE CHARACTERISTICS } \\
\hline Age & $46.1(16.3)$ & $50.8(9.4)$ & $0.54^{*}$ \\
\hline Gender (male/female) & $2 / 6$ & $4 / 2$ & $0.27^{\dagger}$ \\
\hline Inpatient/outpatient & $2 / 6$ & $2 / 4$ & $0.9^{*}$ \\
\hline MADRS & $32.0(8.0)$ & $29.8(6.9)$ & $0.59^{*}$ \\
\hline \multicolumn{4}{|c|}{ AFTER 5 rTMS SESSION } \\
\hline MADRS decrease (\%) & $-15.39(12.02)$ & $-19.78(10.57)$ & \\
\hline Responders (\%) & 0 & 0 & \\
\hline \multicolumn{4}{|c|}{ AFTER 10 rTMS SESSION } \\
\hline MADRS decrease (\%) & $-22.18(22.65)$ & $-34.95(14.95)$ & \\
\hline Responders (\%) & 25 & 50 & \\
\hline \multicolumn{4}{|c|}{ AFTER 15 rTMS SESSION } \\
\hline MADRS decrease (\%) & $-29.72(34.79)$ & $-47.11(19.29)$ & \\
\hline Responders (\%) & 37.5 & 66.7 & \\
\hline \multicolumn{4}{|c|}{ AFTER 20 rTMS SESSION } \\
\hline MADRS decrease (\%) & $-51.25(35.35)$ & $-52.96(21.58)$ & \\
\hline Responders (\%) & 50 & 66.7 & \\
\hline
\end{tabular}

rTMS: repetitive transcranial magnetic stimulation/MADRS: MontgomeryAsberg Depression Rating Scale. Results are given as mean (SD).

${ }^{*}$ Student $t$-test; ${ }^{\dagger}$ Fischer Chi-square test.

Responders were defined as patients with a MADRS score $<15$.

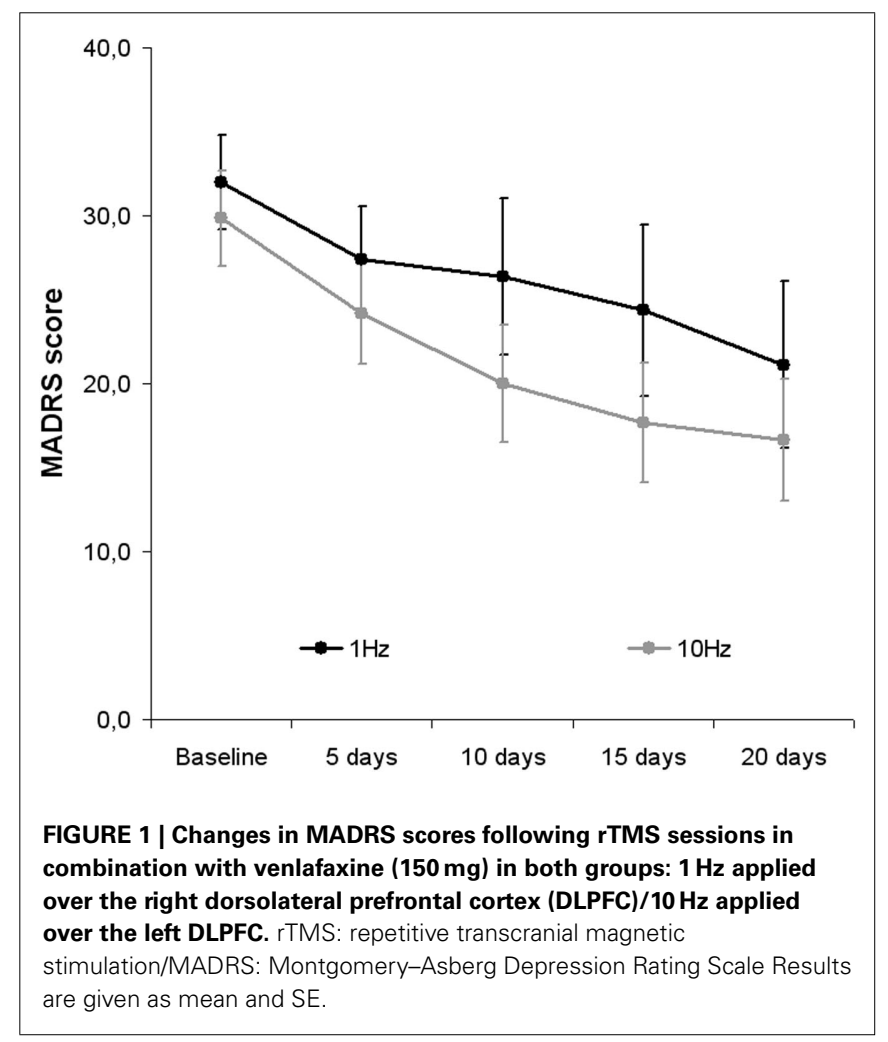

group ( $\mathrm{HF}$ or LF) and time $\left[F_{(4,44)}=0.61 ; p=0.66\right]$, suggesting that decreases of MADRS scores were comparable in both groups (Figure 1). 


\section{DISCUSSION}

Our results replicate and extend previous findings showing that DLPFC LF-rTMS administered on the right side results in a similar effect compared to left-sided DLPFC HF-rTMS (Höppner et al., 2003; Isenberg et al., 2005; Stern et al., 2007; Fitzgerald et al., 2009; Pallanti et al., 2010; Rossini et al., 2010). Despite a failure in response to one previous $\mathrm{AD}$, we reported that some patients could be considered as responders only 2 weeks after the start of treatment and after 4 weeks, more than a half of group could be qualified as responders as defined by a MADRS score $<15$.

In combination with venlafaxine $(150 \mathrm{mg} /$ day $), 120$ pulses/ session of LF-rTMS over the RDLPFC (delivered during $4 \mathrm{~min}$ ) could be as effective as 2000 pulses/session of HF-rTMS over the left DLPFC (delivered during $16 \mathrm{~min}$ ). As the most serious potential side effect of rTMS is seizure, and that LF-rTMS may be protective against it (Theodore et al., 2002), thus, more than saving the user and patient time, LF-rTMS should be a treatment of choice for patients.

We have observed no relapse during the study period (4 weeks) but a follow up period is required before any conclusion on this point. We reported no adverse events in the combination of medication.

The lack of an arm with placebo venlafaxine in association with active rTMS and of an arm with active venlafaxine and sham rTMS are some limitations of our study. However, it has been reported that $1 \mathrm{~Hz}$ rTMS is as effective as venlafaxine in

\section{REFERENCES}

Baldomero, E. B., Ubago, J. G., Cercós, C. L., Ruiloba, J. V., Calvo, C. G., and López, R. P. (2005). Venlafaxine extended release versus conventional antidepressants in the remission of depressive disorders after previous antidepressant failure: ARGOS study. Depress. Anxiety 22, 68-76.

Bares, M., Kopecek, M., Novak, T., Stopkova, P., Sos, P., Kozeny, J., Brunovsky, M., and Höschl, C. (2009). Low frequency (1-Hz), right prefrontal repetitive transcranial magnetic stimulation (rTMS) compared with venlafaxine ER in the treatment of resistant depression: a double-blind, single-centre, randomized study. J. Affect. Disord. 118, 94-100.

Brunelin, J., Poulet, E., Boeuve, C., Zeroug-Vial, H., D'Amato, T., and Saoud, M. (2007). Efficacy of repetitive transcranial magnetic stimulation (rTMS) in major depression. Encephale 33, 126-134.

Fava, M. (2003). Diagnosis and definition of treatment-resistant depression. Biol. Psychiatry 53, 649-659.

Fitzgerald, P. B., Hoy, K., Daskalakis, Z. J., and Kulkarni, J. (2009). A randomized trial of the anti-depressant

the treatment of resistant depression (Bares et al., 2009). Moreover, it is important to note that in a large randomized controlled trial using venlafaxine alone (Rush et al., 2006), with a demographic comparable depressed group, among the patients who had a remission (24.8\% of the sample), the mean time to remission was $5.5 \pm 4.7$ weeks (median, 4.2). We reported more than $50 \%$ decrease of MADRS score after 4 weeks of treatment while a $30 \%$ decrease of HDRS was reported in a large study investigating the impact of venlafaxine after previous $\mathrm{AD}$ failure (Baldomero et al., 2005). On the other hand, as it seems to be the case in our results, Rumi et al. (2005) have reported that in add-on therapy rTMS may be able to accelerate the delay efficacy of AD.

In conclusion, although limited by small sample size and lack of venlafaxine placebo arm, in a sample of patients who have not responded to one trial of antidepressant medication, in combination with venlafaxine $150 \mathrm{mg} /$ day, right-sided LF-rTMS seems as effective as left-sided HF-rTMS. In order to investigate the real impact of LF-rTMS without any antidepressant treatment compared to rTMS in add-on therapy with venlafaxine and to venlafaxine alone, we have started a large multicentric study (clinicaltrials.gov; NCT00714090).

\section{ACKNOWLEDGMENTS}

This work was supported by the Conseil Scientifique de la Recherche (CSR), CH le Vinatier. Mondino Marine held a doctoral fellowship from la Région Rhône-Alpes.

Montgomery, S. A., and Asberg, M. (1979). A new depression scale designed to be sensitive to change. Br. J. Psychiatry 134 383-389.

Pallanti, S., Bernardi, S., Di Rollo, A., Antonini, S., and Quercioli, L. (2010). Unilateral low frequency versus sequential bilateral repetitive transcranial magnetic stimulation: is simpler better for treatment of resistant depression? Neuroscience 167, 323-328.

Poulet, E., Brunelin, J., Boeuve, C., Lerond, J., D’Amato, T., Dalery, J., and Saoud, M. (2004). Repetitive transcranial magnetic stimulation does not potentiate antidepressant treatment. Eur. Psychiatry 19, 382-383.

Rossini, D., Lucca, A., Magri, L., Malaguti, A., Smeraldi, E., Colombo, C., and Zanardi, R. (2010). A symptom-specific analysis of the effect of high-frequency left or lowfrequency right transcranial magnetic stimulation over the dorsolateral prefrontal cortex in major depression. Neuropsychobiology 62 91-97.

Rumi, D. O., Gattaz, W. F., Rigonatti, S. P., Rosa, M. A., Fregni, F., Rosa, M. O., Mansur, C. Myczkowski, M. L., Moreno, R.
A., and Marcolin, M. A. (2005). Transcranial magnetic stimulation accelerates the antidepressant effect of amitriptyline in severe depression: a double-blind placebocontrolled study. Biol. Psychiatry 57, 162-126.

Rush, A. J., Trivedi, M. H., Wisniewski, S. R., Stewart, J. W., Nierenberg, A. A., Thase, M. E., Ritz, L., Biggs, M. M., Warden, D., Luther, J. F., ShoresWilson, K., Niederehe, G., and Fava $\mathrm{M}$ for the $\operatorname{STAR}^{\star} \mathrm{D}$ Study Team. (2006). Bupropion-SR, sertraline, or venlafaxine-XR after failure of SSRIs for depression. N. Engl. J. Med. 354, 1231-1242.

Steffens, D. C., Krishnan, K. R., and Helms, M. J. (1997). Are SSRIs better than TCAs? Comparison of SSRIs and TCAs: a meta-analysis. Depress. Anxiety 6, 10-18.

Stern, W. M., Tormos, J. M., Press, D. Z., Pearlman, C., and Pascual-Leone, A. (2007). Antidepressant effects of high and low frequency repetitive transcranial magnetic stimulation to the dorsolateral prefrontal cortex: a double-blind, randomized, placebo-controlled trial. J. Neuropsychiatry Clin. Neurosci. 19, 179-186.

for antion of the left frontal co resistant depressed patients. Ann. Clin. Psychiatry 17, 153-159.
Theodore, W. H., Hunter, K., Chen, R., Vega-Bermudez, F., Boroojerdi, B., 
Reeves-Tyer, P., Werhahn, K., Kelley, K. R., and Cohen, L. (2002). Transcranial magnetic stimulation for the treatment of seizures: a controlled study. Neurology 59, 560-562.

Conflict of Interest Statement: The authors declare that the research was conducted in the absence of any commercial or financial relationships that could be construed as a potential conflict of interest.

Received: 31 October 2011; accepted: 12 February 2012; published online: 07 March 2012.

Citation: Eche J, Mondino M, Haesebaert F, Saoud M, Poulet E and Brunelin
$J$ (2012) Low-vs high-frequency repetitive transcranial magnetic stimulation as an add-on treatment for refractory depression. Front. Psychiatry 3:13. doi 10.3389/fpsyt.2012.00013

This article was submitted to Frontiers in Neuropsychiatric Imaging and Stimulation, a specialty of Frontiers in Psychiatry.
Copyright (c) 2012 Eche, Mondino, Hae sebaert, Saoud, Poulet and Brunelin. This is an open-access article distributed under the terms of the Creative Commons Attribution Non Commercial License, which permits non-commercial use, distribution, and reproduction in other forums, provided the original authors and source are credited. 